\title{
Gênero e Sexualidades nas aulas de Sociologia: um olhar sobre a percepção discente
}

Stephanie Natalie Burille ${ }^{1}$

Resumo: O presente artigo tem como objetivo principal discutir as percepções de gênero de estudantes de uma escola pública de Cuiabá durante as aulas de Sociologia. Partindo deste objetivo, as enunciações dos estudantes foram fundamentais para a compreensão das representações de gênero no universo escolar. A metodologia consistiu na realização do trabalho de campo na escola e entrevistas semiestruturadas com os estudantes de ensino médio. Conforme resultados, constatou-se que nas aulas de Sociologia os estudantes apresentavam práticas e expressões sexistas. Conclui-se que há limites para a abordagem de gênero na disciplina de Sociologia, por isso se faz necessário dar visibilidade às teorias que incrementam o discurso da diversidade e da diferença na escola.

Palavras-chave: Gênero; Ensino; Sociologia.

Abstract: This article aims to discuss the gender perceptions of students from a public school in Cuiabá during the Sociology classes. Taking as its starting point, the student's enunciations were fundamental to the comprehension of gender representations in the school universe. The methodology consisted in field work in the school and semi-structured interviews with the high school students. According to results, it was found that in the Sociology classes students had practices and expressions of sexist slant. It is concluded that there are limits to the gender approach in Sociology discipline, so it is necessary

\footnotetext{
${ }^{1}$ Graduanda em Ciências Sociais pela Universidade Federal do Mato Grosso (UFMT); Bolsista de Iniciação Científica (UFMT/FAPEMAT) sob orientação da Prof ${ }^{a}$. Dr ${ }^{a}$ Silvana Maria Bitencourt. E-mail: stephanie.burille@ hotmail.com.
} 
to give visibility to theories to increase the discourse of diversity and difference in school.

Keywords: Gender; Education; Sociology.

\section{Introdução}

Entre as inúmeras problemáticas que adentram a escola, há uma inquietação por parte de alguns estudiosos (CARVALHO, 2012; LOURO, 1997) acerca do preconceito de gênero permeado nas relações sociais no contexto escolar. Este artigo discute, a partir da perspectiva de estudantes do ensino médio, quais as representações de gênero que perpassam o imaginário desses indivíduos, especialmente quando construídas no contexto das aulas de Sociologia. Para tanto, utilizou-se as reflexões de autoras como Judith Butler (2008), Maria Teresa Citeli (2001), Guacira Louro (1997) e Joan Scott (1995), estas que contribuíram para o desenvolvimento de novas reflexões nesta área de estudos de gênero. Ao longo deste estudo ${ }^{2}$ procuramos conhecer a realidade da escola pública cuiabana, por meio de um olhar voltado à forma de como são construídas e compreendidas as relações de gênero no universo escolar.

\footnotetext{
${ }^{2}$ Este trabalho consiste em uma parte condensada da pesquisa desenvolvida durante o período de agosto de 2013 a julho de 2014 intitulado: "Qual conteúdo ministrado nas aulas de Sociologia para a promoção de uma educação não sexista nas escolas públicas de Cuiabá?" vinculado ao programa de bolsas de Iniciação Científica da UFMT.
} 
Em relação à metodologia utilizada nesta pesquisa, decidiu-se trabalhar com a metodologia qualitativa a fim de desenvolver uma análise mais eficaz sobre os significados das relações sociais presentes no cotidiano escolar. Nesse sentido, realizou-se pesquisa de campo durante o período de três meses em dez turmas de ensino médio. Também foram aplicadas 18 entrevistas semiestruturadas com os estudantes, entre eles nove meninos e nove meninas de idades entre 15 e 18 anos. O tempo de cada entrevista foi em média 20 minutos, considerando que se levou cerca de três horas para suas transcrições.

O contexto das aulas de Sociologia apresentou-se como o lócus principal da pesquisa, pois foi nestas aulas que se constituíram o espaço onde as relações de gênero foram analisadas para compreender em que medida o gênero está operando a partir dos conteúdos ministrados nas aulas de Sociologia. Neste texto, compartilhamos a definição de gênero a partir de Joan Scott: "o gênero é um elemento constitutivo de relações sociais baseadas nas diferenças percebidas entre os sexos e o gênero é uma forma primária de dar significado às relações de poder" (1995, p. 86).

Ademais, foi possível verificar o que os estudantes da escola "Arruda" 3 pensam a respeito das representações sobre o "ser homem" e o "ser mulher", representações estas que refletem em diferenças sociais

\footnotetext{
${ }^{3}$ Identificarei como "Arruda" o nome fíctício da escola pública estadual de Cuiabá que realizei observação participante durante o desenvolvimento da pesquisa iniciada em agosto de 2013 e finalizada em julho de 2014 a fim de preservar a identidade da mesma.
} 
que, por vezes, naturalizadas, revelam as desigualdades de gênero. De acordo com Moscovici (2007), toda cognição, motivação e comportamento só existem se significarem algo por definição, ou se uma mesma linguagem, signos, valores e memórias forem compartilhados entre as pessoas. As representações são sociais, portanto, simbólicas.

Todas as explicações dependem da ideia que os indivíduos têm acerca da realidade. Nesse sentido, as representações sociais dos estudantes de ensino médio estão relacionadas às suas percepções de mundo, sendo elas internalizadas de acordo com as experiências vivenciadas e os universos simbólicos compartilhados em seus contextos sociais. Por isso, durante o trabalho de campo verificamos a necessidade da realização de entrevistas em profundidade a fim dos estudantes enunciarem seus posicionamentos a respeito do gênero e da sexualidade.

Sobre o uso de entrevistas, Gaskell (2010) salienta que: esta fornece dados básicos para a compreensão das relações entre os atores sociais, assim como é capaz de fornecer uma "descrição detalhada" de um meio social específico. O objetivo de utilizar tal método está em compreender a fundo elementos de crença, atitudes, valores e motivações das pessoas nos contextos sociais específicos (BAUER; GASKELL, 2010, p. 65). Assim, colaborando para a possibilidade de 'mergulhar' nesse universo de representações dos indivíduos em questão. 
Segundo Bitencourt (2013), é a partir da percepção do aluno, muitas vezes ignorado diante da dicotomia presente na relação professor/dono do saber versus aluno/sem conhecimento, que se busca entender essa outra perspectiva. A autora ainda complementa que: dar voz ao estudante contribui para romper a "viciada" dicotomia entre estudante/professor, a fim de promover uma relação mais colaborativa entre o conteúdo sociológico e a "realidade" escolar.

Partindo do exposto, o presente artigo consiste em três momentos. No primeiro momento realizamos uma revisão bibliográfica sobre os conceitos de gênero e educação; no segundo momento apresentamos os resultados e as discussões acerca do universo simbólico compartilhado pelos estudantes da escola "Arruda"; finalizando com algumas considerações sobre o trabalho desenvolvido.

\section{Conceito de Gênero}

Em relação ao discurso científico do século XIX, podemos constatar que historicamente o discurso biológico foi construído por valores culturais da sociedade ocidental, assim fundamentando a produção de uma ciência que aglutinava as diferenças consideradas naturais e sociais, sendo que umas justificavam as outras. Maria Teresa Citeli (2001) reflete sobre o determinismo biológico que legitimou a biologia para falar das distinções fisiológicas e anatômicas de homens e mulheres como argumentos que explicavam as diferenças dos 
comportamentos e as desigualdades sociais. O conhecimento científico visto como único e verdadeiro na modernidade, ainda envolve um grande respaldo social para a opinião pública, portanto é um significativo instrumento de dominação que legitima a hierarquia e o poder nas relações de gênero. Segundo Citeli (2001),

Quase um século depois, desnaturalizar hierarquias de poder baseadas em diferenças de sexo tem sido um dos eixos centrais dos estudos de gênero. Estabelecer a distinção entre os componentes natural/biológico em relação a sexo e social/cultural em relação ao gênero - foi, e continua sendo, um recurso utilizado pelos estudos de gênero para destacar essencialismos de toda ordem que há séculos sustentam argumentos biologizantes para desqualificar as mulheres, corporal, intelectual e moralmente. (2001, p. 132)

Conforme Thomas Laqueur (2001), anterior ao período renascentista do século XV não havia uma terminologia anatômica que distinguisse a genitália feminina e masculina. $\mathrm{O}$ que supostamente ocorria era uma retenção interna do sexo da mulher, causado por uma falta de calor vital que resultava na imperfeição da estrutura corporal. A anatomia do corpo humano e seus processos fisiológicos eram baseados unicamente no modelo de estrutura corporal masculino.

No final do século XVIII surgiram novas formas de interpretação do esqueleto humano conduzido pelo dimorfismo e divergência biológica, que a partir de então modificaria os significados das diferenças sexuais. Justificar na biologia as diferenças sexuais, e 
assim justificar os papéis sociais destinados aos homens e às mulheres, é atribuir um sentido legítimo às desigualdades sociais.

Conforme Joan Scott (1995), o uso do termo "gênero" passou a ser empregado pelo movimento feminista a fim de se referir a uma organização social dos sexos e promover a distinção entre o determinismo biológico e os papeis sociais de homens e mulheres, que até então estavam vinculados a um mesmo sentido. Falar de "gênero" é designar às relações sociais e as identidades subjetivas que emergem de construções culturais.

Além disso, enquanto preocupação teórica e política que torna o gênero uma categoria de análise histórica a partir das reflexões feministas que marcaram especialmente o século $\mathrm{XX}$, também são implicados significados para as relações de poder em meio às interações humanas.

De tal modo, analisar a partir da categoria gênero subentendese assumir uma perspectiva transversal, em que outras categorias sociológicas como: classe, raça, gênero, religião e geração devem ser considerados relevantes para se analisar as desigualdades.

Inicialmente procuravam-se explicações para as origens do patriarcado, em que as mulheres eram submissas aos homens que detinham o poder na família; logo se estudou a categoria pelo viés marxista preocupado em questionar as desigualdades a partir das relações de produção. Ulteriormente, a escola francesa e a escola angloamericana estiveram preocupadas com a formação das identidades de 
gênero com influência em teorias da psicanálise. Dessa forma, ocorre uma sofisticação conceitual até ser compreendida como uma categoria analítica das relações sociais.

Uma questão que Louro (1997) enfatiza na argumentação de Scott (1995) é a oposição binária rígida entre masculino e feminino retratada na sociedade. $\mathrm{O}$ caráter dicotômico insere o gênero em um sistema de dominação e submissão que precisa ser desconstruído. Romper com a lógica polarizante conduz a atenção para as diversas pluralidades de gênero, e não somente as singularidades existentes entre feminilidades e masculinidades. Portanto, no espaço da escola pode-se dar visibilidade a outras identidades de gênero.

A autora Judith Butler (2008), a partir de uma abordagem pósestruturalista, contribui para pensarmos gênero no sentido performativo para além de identidades fixas ou categorias de corpo, sexo, gênero e sexualidade que perpassam a estrutura binária, mas enquanto expressividades e significados. Conforme Bitencourt (2013), Butler questiona essa estrutura que oferece uma legitimidade para o sujeito existir, enquadrando-o em uma categoria que reforça a ideia de masculino/feminino de matriz heterossexual (2013, p. 183).

\section{Gênero e Educação}

O sujeito que usufrui da instituição responsável pelo saber e aprendizado é também conduzido por um conjunto de regras e valores, 
pelos quais, como afirma Durkheim (1978), produz e reproduz indivíduos de acordo com padrões de socialização e um modelo de educação adequado para sua inserção social.

A instituição escolar é reprodutora da cultura dos grupos e classes dominantes, do mesmo modo que proporciona a reprodução da estrutura das relações de força, como afirmam Bourdieu e Passeron (1982). Compreende-se, na visão dos autores, que a escola é mantenedora da cultura imposta pela classe dominante, e dessa forma, sustenta um sistema social de desigualdades que refletem diretamente na construção do aprendizado e das relações sociais. Em relação ao sistema escolar, Bourdieu salienta que: "é um dos fatores mais eficazes de conservação social, pois fornece a aparência de legitimidade às desigualdades sociais, e sanciona a herança cultural e o dom social tratado como dom natural" (1998, p.41).

Ao depararem com a escola e o perfil educacional proposto para orientá-los a determinado conhecimento, Louro (1997) esclarece que esses sujeitos aprendem a incorporar discursos, modos de ser e agir, preferências e identidades que se formam sob arranjos de normas, regras e os "bons costumes" que a escola tende a preservar.

Portanto, a escola está para além de somente produzir e transmitir conhecimentos. Ela "fabrica" sujeitos, molda-os de acordo com as convenções e padrões sociais de "normalidade" fortemente instituídos. Nesse aspecto, o que não se integra aos padrões, não encontra espaço no ambiente escolar, ou seja, não encontra visibilidade 
e reconhecimento, permanecendo na condição de excluído. Louro afirma que a escola silencia questões relacionadas às identidades de gênero que escapam da dicotomia feminino/masculino, assim como, de concepções de sexualidade que não se enquadram na perspectiva heteronormativa.

A incorporação dos valores femininos e masculinos está no que Bourdieu conceitua como habitus ${ }^{4}$. No caso dos estudantes de ensino médio das escolas públicas, é possível refletir esse conceito nas atividades que eles desenvolvem, a maneira como praticam esportes, como se comportam em sala de aula, suas opiniões políticas, bem como, seus modos e estilos de vida.

A sala de aula, o pátio, a quadra de esportes, os banheiros, a sala dos professores, enfim, todo o espaço que configura a escola é formado por ambientes que inscrevem signos, marcas, características que ora proporcionam interações, ora limitam espaços na medida em que as diversidades de gênero e de sexualidade se defrontam. Nesse contexto, as diferenças de gênero são exacerbadas e expressas nos discursos, nos gestos, nos "modos" de se relacionar.

Apesar de existir uma regulamentação institucional que corrobore para que a pauta da diversidade de gênero e sexualidade esteja embasada nas orientações curriculares da instituição escolar, o padrão predominante das identidades masculina e feminina, sobretudo o

\footnotetext{
${ }^{4}$ Conceito de habitus em Bourdieu é "o princípio gerador de práticas objetivamente classificáveis e, ao mesmo tempo, sistema de classificação (principium divisionis) de tais práticas." BOURDIEU, 2007, p. 162.
} 
modelo "normal" de sexualidade abalizada na heteronormatividade, é o que de fato orienta os comportamentos dos indivíduos. O que é visto e compreendido como "fora" do padrão e o que condiz com o "diferente" não faz parte das práticas aceitáveis e sustentadas socialmente, reforçando ainda mais a afirmação da identidade de gênero como única, singular, logo, permitida (LOURO, 2003).

A escola é o espaço onde existem barreiras que impedem a expressão das diferenças. Os padrões são reforçados e reproduzidos constantemente. Ser e agir de maneira "normal" é uma exigência por parte do contexto escolar e dos próprios estudantes. Aquele que não se adéqua às convenções, não é integrado ao meio. Isso é verificado, por exemplo, em dizeres que apontam uma profunda aversão aos que não assumem uma identidade heterossexual.

Uma situação vivenciada durante o trabalho de campo na aula de Sociologia ilustra melhor esta questão. Ouvimos um estudante afirmar, em meio a uma discussão sobre a constituição de famílias homoafetivas, que gay tem que morrer mesmo, ou então outro colega afirmando que meninos que usam maquiagem e batom não merecem respeito, podemos evidenciar uma agressividade tão intensa que contraria as expectativas depositadas na escola ${ }^{5}$ de 'metamorfosear' esses adolescentes em adultos reflexivos, com uma visão mais humanística, ou seja, sendo estes capazes de transformar a realidade.

\footnotetext{
${ }^{5}$ Esta expectativa em relação a transformar o estudante em um ser reflexivo podemos constatar a partir dos objetivos dos Parâmetros Curriculares Nacionais do ensino médio, principalmente em relação as disciplinas de Filosofia e Sociologia.
} 
Segundo Ileizi Silva (2005), além da preocupação em formar trabalhadores, o ensino médio tem a responsabilidade de formar sujeitos sociais, bem como auxiliar no direcionamento da vida desses jovens e também, contribuir para que formulem uma compreensão racional e crítica dos sentidos culturais e da natureza. A tolerância, a autonomia intelectual e a formação de personalidades devem ser produtos de um ensino eficaz que direcione as capacidades de convívio coletivo que caminhe para a promoção da igualdade de gênero. Nesse viés, a Sociologia se faz importante na educação básica para a formação de sujeitos conscientes e sensíveis às questões sociais que permeiam seus cotidianos.

De acordo com Silva (2005), desde 1940 o papel da Sociologia na escola vem sendo discutido no Brasil. Enquanto disciplina do Ensino Médio, é pensado a partir de 1996, na promulgação da Lei de Diretrizes e Bases da Educação Nacional-LDBEN, com o objetivo de preparar jovens e adolescentes estudantes para uma formação mais humanitária do saber, o que corresponde a uma construção processual. "O objetivo do ensino de Sociologia é o de modificar os padrões de envolvimento e distanciamento dos jovens em relação à vida social." (SILVA, 2005, p. 11). A autora se refere a envolvimento no sentido de compreender os fenômenos sociais, possibilitando, assim, novas explicações e uma maior aproximação com essas realidades. $\mathrm{O}$ distanciamento se refere à compreensão e estranhamento do meio social em que estão inseridos, os 
conhecimentos aprendidos na escola, os valores religiosos, ou seja, fenômenos reconhecidos como "naturais".

E qual seria o papel do professor de Sociologia enquanto detentor do conhecimento científico acerca da disciplina? Segundo Silva (2005), o professor deve seguir um rigor científico que o permita oferecer aos estudantes o acúmulo de conhecimento da disciplina. Weber (1993) já nos dizia sobre a necessidade de discernir a docência enquanto vocação racional-legal de posições partidárias, ideológicas e religiosas.

Ao tratar de temas transversais, como no caso de gênero e sexualidades, é recomendada a formação desse professor em estudos de gênero a fim de abordar tais questões com ética, seriedade e conhecimento, para então, fomentar a desconstrução de preconceitos e visões fundamentadas no senso comum ou em valores morais e religiosos presentes nos discursos.

As observações em sala de aula provocaram uma reflexão sobre esse sistema de ensino vigente e as possibilidades que a sociologia nos proporciona em trazer à sala de aula um ensino voltado para a autonomia intelectual do estudante no sentido de questionar as estruturas consolidadas pelo modelo heteronormativo de sociedade. Neste sentido, apresentamos a seguir as análises sobre as experiências em sala de aula, assim como as percepções dos estudantes quanto à questão de gênero nas aulas de Sociologia. 


\section{Quem são estes estudantes?}

Em relação ao perfil ${ }^{6}$ dos dezoito estudantes entrevistados da escola "Arruda" que frequentam as aulas de Sociologia, constatou-se que estes compõem a faixa etária média de dezesseis anos de idade. Em maioria, os estudantes integram um núcleo familiar formado pelo pai, a mãe e um ou mais irmãos e irmãs, sendo a maior parte deles filhos ou filhas mais novos. Grande parte dos entrevistados estuda nessa escola há cerca de dois ou três anos consecutivos. Em relação à religiosidade, contabilizaram-se seis estudantes adeptos à religião evangélica, cinco estudantes católicos, e sete estudantes que afirmaram não ter religião. Dentre os entrevistados, há um total de oito alunos que além de frequentarem a escola, afirmam trabalhar; destes, sendo sete meninas e um menino. Os outros estudantes somam-se dez, que afirmam dedicarse somente aos estudos; destes, sendo somente duas meninas e oito meninos exclusivamente estudantes. Portanto, verifica-se que há um contingente maior de mulheres que além de estudantes, são desde já trabalhadoras. Estes estudantes foram interrogados sobre o porquê das diferenças de gênero.

\footnotetext{
${ }^{6} \mathrm{O}$ perfil dos estudantes foi traçado a partir de um roteiro de entrevista específico com perguntas direcionadas a esse propósito.
} 


\section{O mercado de trabalho e as relações de gênero}

$\mathrm{O}$ fato da maioria das meninas trabalharem enquanto a maioria dos meninos ainda não trabalha é um dado importante, pois denota que há uma demanda maior por parte das mulheres em se inserirem no mercado de trabalho precocemente. Logo, se considerarmos o modelo patriarcal vigente na sociedade brasileira, essa decisão das meninas por trabalhar fora pode ser compreendida como uma hipótese para a conquista de maior autonomia e independência financeira, logo, rompendo o modelo de família patriarcal brasileira. Vale a pena salientar que a sociedade vem passando por transformações consideráveis, possibilitando uma maior inserção feminina nos espaços públicos nas últimas quatro décadas, especialmente em carreiras/profissões consideradas socialmente masculinas. Nesse sentido, estes estudantes quando indagados sobre as diferenças de gênero na sociedade, grande parte deles apontou que verificam essas diferenças principalmente no mercado de trabalho, alegando que o homem se sobressai em relação à mulher. Afirmar que as mulheres são diferentes dos homens remete à ideia de que a mulher não atinge todas as expectativas profissionais, ou seja, há incapacidade feminina ao assumir determinadas atividades que durante muito tempo estiveram atreladas ao universo masculino, por exemplo, as profissões consideradas culturalmente masculinas por exigir força, raciocínio lógico e objetividade. 
Esta ideia de "incapacidade" feminina decorre do habitus, isto é, o processo pelo qual "verdades" são inculcadas durante a socialização primária e que fazem parte da construção individual e coletiva de cada indivíduo. Desde o período da infância verifica-se que muitos pais ainda não estimulam suas filhas a interagirem com brinquedos de meninos, $\mathrm{e}$ vice-versa. Há uma diferenciação de gênero nesse aspecto que já condicionam certas aspirações desde criança. Conforme a autora Londa Schienbinger (2001),

Dar a meninas e meninos brinquedos diferentes poderia ser inofensivo, exceto pelo fato de que brinquedos criam aspirações, afiam aptidões conceituais e estimulam certos comportamentos em detrimento de outros (SCHIENBINGER, 2001, p. 117).

Desta forma, enquanto meninas são incentivadas a brincar de casinha, bonecas e panelinhas, os meninos são motivados a interagir desde cedo com carros, brinquedos de raciocínio lógico ou que estimulam o gosto pelo esporte. Essa internalização das diferenças e oposições entre masculino e feminino está na relação com brinquedos, no incentivo que há para os meninos pela área das exatas, enquanto as meninas se inclinam para a área das humanas, e tende a refletir na relação com o mercado de trabalho.

Partindo desta perspectiva, é importante verificar que a maioria das meninas entrevistadas já está inserida no mercado de trabalho, o que pode demonstrar que há uma pressão social maior para elas alcançarem 
sucesso nos espaços públicos, e assim comprovarem as suas capacidades. Segundo Bitencourt (2006),

[...] estas mulheres precisarão incorporar uma determinada linguagem para interagir dentro deste espaço e estabeleceram determinadas táticas para sobreviver com as suas diferenças de gênero construídas socialmente e historicamente. (BITENCOURT, 2006, p. 42)

Historicamente a figura feminina era associada ao espaço privado, tendo uma função social ligada aos afazeres domésticos, enquanto a figura masculina estava mais associada à esfera pública. Portanto, ainda que tenham existido transformações históricas e culturais sobre as ressignificações dos espaços públicos e privados em relação ao universo masculino e feminino, pode-se verificar que ainda há dificuldade da mulher em se inserir e ascender no mercado de trabalho, encontrando, muitas vezes, resistências e preconceitos, como observado na fala de uma estudante, abaixo:

[...] com mulher acontece mais a discriminação... mais com mulher. É que assim, todo mundo fala que mulher foi feita pra ficar em casa e tudo, mas pra mim isso é... porque eu já vi muita mulher sendo... saindo do trabalho porque o homem ia vim e ocupar o cargo dela. Isso já aconteceu comigo já. [...] foi num outro escritório que eu trabalhava com o amigo do meu vô. E ai entrou um rapaz e como ele, assim... dizia que era muito mais ágil que eu, então... [...] ele fazia mais coisa pelo fato de ele ser homem, né. "Ah, então ele vai carregar isso e você não 
consegue" e não sei o que... então eles mandaram eu embora [...] (Ana, estudante do $1^{\circ}$ ano)

Nesse discurso entendemos que o mercado de trabalho é um espaço de privilégio masculino. Fazer parte deste meio requer incorporar aspectos da masculinidade e interagir com esse universo simbólico. Deste modo, no mercado de trabalho há diversas barreiras para a entrada e manutenção do "sexo frágil".

\section{O Gênero e a socialização primária}

Sobre a origem das diferenças entre homens e mulheres na sociedade, quando questionados, muitos estudantes não souberam explicar de forma esclarecida, alegando somente que as diferenças "vêm de antigamente". Nesse sentido, percebe-se uma dificuldade dos estudantes em associar um fenômeno social interligado com um processo histórico e cultural. Por isso a importância do professor de Sociologia em abordar as questões de gênero a partir dos conteúdos sociológicos e referências clássicas como: Émile Durkheim e Pierre Bourdieu.

Ainda no âmbito das diferenças de gênero, os estudantes relataram atividades praticadas de maneiras distintas por meninos e meninas na escola. Muitos estudantes relataram que durante a educação física e na hora do intervalo, a quadra de esportes é um espaço predominantemente masculino. Enquanto o futebol é um exercício 
designado aos meninos, as meninas costumam jogar vôlei, conversar ou se entreter com o aparelho celular. Alguns estudantes justificam que as meninas "não se interessam", "não gostam", "preferem" ou "optam" por não praticar esportes. Em meio aos relatos, uma estudante afirma que as meninas, ao manifestarem interesse em jogar futebol, acabam gerando conflitos com os meninos e por isso evitam o espaço:

Os meninos jogam e se a gente fala que quer jogar é uma briga que... sem tamanho, que eles não querem deixar. Tanto pode ser observado na hora do intervalo, que você chega lá na quadra e só tem homem jogando. Não tem mulheres jogando. [...] às vezes a gente fica quieta, né, pelo simples motivo de não querer, vamos dizer, arrumar alguma discórdia com eles [...] (Maria, estudante do $3^{\circ}$ ano)

[...] tem umas diferenças sim, mas é mais, tipo educação física, assim, aí tem bastante, às vezes é separado, é futsal que os meninos gostam muito, então mais os meninos jogam [...] (Joana, estudante do $2^{\circ}$ ano)

Estes discursos remetem ao que Bourdieu (2014) especifica como manifestação simbólica do poder. A dominação masculina está imersa nas práticas que submetem as mulheres a situações de "proibição" implícita, como ocupar determinados espaços sociais simbolicamente masculinos, e um "consentimento" das mulheres em não fazer parte desses espaços e dessas práticas. Nisso, diz-se então que as mulheres "preferem" ou "optam" pela escolha de não adentrar estes espaços. $O$ fato é que há uma delimitação imposta, que não 
necessariamente precisa ser dita, mas é reforçada por uma "conformação" silenciada.

\section{Gênero na escola}

Ao serem questionados se o conteúdo de gênero e sexualidade havia sido discutido em outros anos do ensino médio ou ensino fundamental, seja em Sociologia ou em outras disciplinas, a maioria dos estudantes afirmou já ter tido algum conhecimento, mesmo que superficial, sobre a temática. No entanto, há uma evidência de que gênero nem sempre é retratado pela perspectiva social e cultural, mas também biológica, no que tangem as diferenças entre os sexos.

A biologia e a educação física são outras áreas de conhecimento que abordam diferenças entre homens e mulheres e sobre sexualidade que remetem às diferenças biológicas, seguindo o caráter de informação e prevenção de doenças sexualmente transmissíveis. Essa abordagem não é suficiente e não corresponde às demandas sociais que existem acerca da problemática. O modo como entendemos $\mathrm{e}$ vivenciamos o corpo é sempre mediado pelas formas de pensamento historicamente construídas (FOUCAULT, 1988). Nesse sentido, tornase primordial discutir a maneira como a escola, as disciplinas e os professores abordam as diferenças. 
Consideramos que a Sociologia como disciplina escolar poderá desenvolver conteúdos e metodologias que promovam uma reflexão mais aprofundada sobre essas percepções de gênero.

\section{As aulas de Sociologia e o professor}

As observações de campo e os relatos dos estudantes demonstraram que a disciplina de Sociologia na escola "Arruda" é uma aula dedicada a debates, rodas de conversas, discussões sobre conteúdos da Sociologia que o professor elenca como fundamentais. No entanto, os usos de materiais de apoio se resumem a filmes, músicas e raramente o uso do livro didático. Também se certificou a ausência de leituras de textos e incentivo no desenvolvimento da escrita.

O ensino de Sociologia tem um caráter de disciplina "mais liberal" na visão dos estudantes. Trata-se de uma aula considerada interativa e descontraída, em que os estudantes conversam entre si, manipulam o aparelho celular a todo o momento, se distraem com as redes sociais, se preocupam com o cabelo, as unhas, a maquiagem, ou qualquer distração, exceto a aula que o professor tanto se esforça em tornar atrativa.

A proposta da aula é ser ensinada a partir de debates sobre assuntos da atualidade, em que o professor questiona os estudantes e os próprios estudantes dialogam sobre o conteúdo sem certa preocupação 
com os conceitos teóricos. A aula é o momento de descontração, o momento de expressar opiniões de cunho pessoal,

[...] porque é onde tem o debate mesmo sobre nosso dia a dia, sobre o que acontece hoje em dia. Mais é sociologia. (Carolina, estudante do $1^{\circ}$ Ano)

Alguns estudantes não deixaram de revelar críticas à didática "livre" do professor e ao próprio conteúdo de Sociologia apresentado. Relatos como a "dificuldade em dar aula" devido à "bagunça" dos alunos se mostraram um fator desestimulante para alunos que poderiam se interessar pela disciplina; assumem não gostar de Sociologia em decorrência do professor; desqualificam a aula como "lenta", onde o professor "enrola" em um único conteúdo:

[...] eu achava muito interessante as aulas de Sociologia quando eu estudava. Aqui o professor é meio... Sei lá, ele puxa um assunto... Ele enrola muito, sabe, na aula. Acho que ele enrola muito. Ele passa o bimestre falando uma coisa só, vai passar pro segundo bimestre e vai falar a mesma coisa. Assim, ele é um bom professor, sabe, mas às vezes eu acho que ele devia desenvolver mais as aulas. (Thiago, estudante do $3^{\circ}$ Ano)

É que ele passa bastante vídeos... Vídeos, música, quase não trabalhamo manual, com caneta, só lendo e prestando atenção, assim. (Lucas, estudante do $1^{\circ}$ Ano)

É neste perfil de aula que o professor de Sociologia aborda o conteúdo de gênero. No período da pesquisa de campo, observou-se que 
as turmas do primeiro ano tiveram parte do bimestre dedicado ao conteúdo. As discussões sobre o tema eram realizadas de modo que as opiniões pessoais dos estudantes e as experiências que vivenciavam no cotidiano fomentavam os debates. O professor utilizava recursos de audiovisual, dinâmicas interativas e rodas de conversa que estimulavam os estudantes a exporem suas formas de pensar o que é "ser homem" e o "ser mulher".

\section{As diferenças que fazem diferenças}

Os entrevistados elencaram algumas características que identificavam outros colegas da escola como pessoas "diferentes". Os colegas gays e as colegas lésbicas foram muito mencionados nas falas desses estudantes, o que condiz com a percepção de que ser homossexual é ser diferente dos demais, e nesse sentido significa romper com um padrão de heteronormatividade rigidamente professado por grande parte dos estudantes. Logo, o que foge ao padrão é o distinto, é o “anormal".

Tem uma menina aqui na escola que ela parece muito um homem porque ela se veste que nem um menino, mas ela é uma menina. E ela se veste assim, mas olhando assim, quem não sabe... eu achava que ela era um menino. Eu fui perceber o ano passado quando ela jogou na equipe feminina. Eu "ué, o que esse menino ta fazendo ai?" que tipo, eu sempre vi ela e não... depois que eu fui descobrir que ela era 
sapatão. Eu não sabia. (Claudia, estudante do $3^{\circ}$ Ano)

As meninas... têm umas meninas que tem a personalidade diferente, o modo de vestir, o modo do cabelo, tem meninas que... é... lésbicas, os meninos já discriminam. A menina fica num canto, e todo mundo, os outros, ficam no outro canto, discriminando porque a pessoa é assim. Eu não acho correto isso porque ela é ser humano, né, ela teria que ser respeitada como ela é. Ela tem que ser respeitada. $\mathrm{Eu}$ acho errado. (Jonas, estudante do $1^{\circ}$ Ano)

O "diferente" passa a ser diferente quando se é revelado que a estudante não se enquadra em determinada categoria de classificação antes adequada ao seu perfil. A menina "sapatão" a quem Claudia antes se referia ao gênero masculino devido ao modo de vestir e se portar passa a ser reconhecida enquanto a menina "que se veste que nem um menino”. A percepção em relação a essa colega é alterada, colocando-a em uma posição de "diferente" dos demais.

Louro (1997) afirma que o ocultamento dos homossexuais na escola é um fator que contribui para que esses estudantes se reconheçam como desviantes, indesejados e ridículos, pois estão confinados às gozações e aos "insultos" dos recreios, das atividades cotidianamente.

Dessa forma, pode-se verificar que a homofobia é outra problemática vivenciada no cotidiano da escola. E neste sentido, há um receio ainda maior de se adentrar na temática da sexualidade. Sempre que abordada essa temática, a biologia é a disciplina que toma frente 
para discussões voltadas para o aspecto de prevenção e informação de doenças sexualmente transmissíveis, desconsiderando a importância de se tratar essas questões por meio de um olhar social e político.

\section{Considerações Finais}

Estes estudantes foram abordados a fim de compreendermos suas percepções sobre gênero nas aulas de Sociologia. De acordo com os dados, pode-se constatar que os estudantes percebem as diferenças de gênero a partir de algumas relações. $O$ mercado de trabalho é verificado como o espaço de maior expressão das diferenças de gênero, segundo os estudantes. Isso decorre das dicotomias entre mulheres e homens, as quais são intensamente marcadas neste espaço. Apesar de assumir um papel mais independente e autônomo, com maiores oportunidades profissionais, as mulheres ainda enfrentam limitações. São elas que precisam se adequar a esse mercado de trabalho que faz parte do universo simbólico masculino.

Outro aspecto verificado foram os valores adquiridos durante a socialização primária, estes que são internalizados no indivíduo por meio do habitus no processo de produção e reprodução das práticas sociais. Tais práticas são aprendidas desde a infância, e por isso se tornam tão difíceis de serem desconstruídas. 
Assim sendo, o papel da Sociologia é imprescindível em vista da promoção de uma igualdade de gênero e a ruptura com uma educação sexista difundida na instituição de ensino. No entanto, existem limitações para o alcance de ressignificações das relações sociais que sejam capazes de confrontar o preconceito de gênero e assim propor uma educação transformadora, à medida que a escola é espaço de reprodução das estruturas sociais atravessadas por um sistema de ensino tradicional e conservador. O conflito geracional entre professores e estudantes, assim como, o papel que as novas tecnologias têm desempenhado na vida dos estudantes são também novos desafios enfrentados pela escola que ainda permanece em um mesmo modelo e estrutura de ensino que não acompanham as mudanças da sociedade.

É necessária uma formação dos professores de Sociologia para lidarem com as questões de gênero e sexualidades. Não basta apenas uma regulamentação institucional a fim de resolver o problema da desigualdade de gênero ou da homofobia entre os estudantes. Também é necessária a disposição destes profissionais da educação em tratarem de temáticas tão complexas e subjetivas, que envolvem valores e crenças absorvidas desde a socialização primária, tanto de cada estudante, quanto dos próprios professores. 


\section{Referencias}

BITENCOURT, Silvana M. Existe um outro lado do rio? Um diálogo entre a cultura da engenharia e relações de gênero no centro tecnológico da UFSC. Florianópolis, SC, 2006. 167f. Dissertação (Mestrado em Sociologia Política). Universidade Federal de Santa Catarina, 2006.

- Quais significados da disciplina Sociologia para o adolescente cuiabano? Um estudo a partir das percepções discentes sobre a Sociologia. In: XXIX Congreso Alas Chile: Crisis Y Emergencias Sociales en América Latina, 2013, Santigo - Chile. Crisis Y Emergencias Sociales en América Latina. Santiago: ALAS, 2013. vol. XXIX, p. 1-12.

A contribuição de teóricas e feministas para os estudos de gênero. Revista Ártemis, vol. XVI, n. 1, ago-dez, 2013, p. 178-185.

BOURDIEU, Pierre; PASSERON, Jean-Claude.Reprodução: elementos para uma teoria do sistema de ensino. Rio de Janeiro, RJ: Francisco Alves, 1982.

BOURDIEU, Pierre. A dominação masculina. Rio de Janeiro: BestBolso, 2014.

. Escritos de educação. In: NOGUEIRA M. A.; CATANI, Afrânio (orgs). Ciências Sociais da Educação. Petrópolis, RJ: Vozes, 1998.

A Distinção: crítica social do julgamento. São Paulo: Edusp; Porto Alegre, RS: Zouk, 2007.

BRASIL. Lei $n^{\circ}$ 9.394. Estabelece as Diretrizes e Bases da Educação Nacional. 20 de dezembro de 1996. 
BUTLER, Judith. Problemas de gênero: feminismo e subversão da identidade. Rio de Janeiro: Civilização Brasileira, 2008.

CARVALHO, Marília Pinto de. Formas de ser menino negro: articulações entre gênero, raça e educação escolar. In: CARVALHO, M. P. (org.) Diferenças e desigualdades na escola. Campinas, SP: Papirus, 2012.

CITELI, Maria Teresa. Fazendo diferenças: teorias sobre gênero, corpo e comportamento. Revistas Estudos Feministas, Florianópolis, vol. 9, n. 1, 2001. p. 131-145.

DURKHEIM, Émile. Educação e Sociologia. São Paulo: Hedra, 2010.

FOUCAULT, Michel. História da Sexualidade I: A vontade de saber. Rio de Janeiro: Edições Graal, 1988.

GASKELL, George. Entrevistas Individuais e Grupais. In:BAUER Martin W.; GASKELL George. Pesquisa qualitativa com texto, imagem e som: um manual prático. 8. Ed. Petrópolis, RJ: Vozes, 2010.p.65-89.

LAQUEUR, Thomas W. Inventando o sexo: corpo e gênero dos gregos a Freud. Rio de Janeiro: RelumeDumará, 2001.

LOURO, Guacira Lopes. Gênero, sexualidade e educação: uma perspectiva pós-estruturalista. Petrópolis, RJ: Vozes, 1997.

. Currículo Gênero e Sexualidade: O normal, o diferente e o excêntrico. In: Louro, Guacira. Corpo, gênero e sexualidade. Um debate contemporâneo na educação. $3{ }^{a}$ Ed. - Petrópolis Ed. Vozes, 2003. p. 41-52.

SCHIENBINGER, Londa. O feminismo mudou a ciência? Bauru, SP: EDUSC, 2001. 
SCOTT, Joan Wallach. Gênero: uma categoria útil de análise histórica. Educação \& Realidade. Porto Alegre, vol. 20, nº 2, Jul./dez. 1995, p. 71-99.

SILVA, Ileizi F. A Sociologia no ensino médio: os desafios institucionais e epistemológicos para a consolidação da disciplina. Natal, RN: Cronos, v. 8, n. 2, p. 403-427, jul./dez. 2007.

Disponível em: http://www.uel.br/grupoestudo/gaes/pages/arquivos/Ileizi\%20-\%20Sociologia\%20 \%20Simposio\%20Curric.\%20E\%20M.doc. Acesso em 25/07/2014.

WEBER, Max. Ciência como vocação. In: - Metodologia das ciências sociais. Parte II. São Paulo: Cortez; Campinas: Ed. UNICAMP, 1993. 